\title{
DIGITALCOMMONS
}

@WAYNESTATE-

Wayne State University

7-20-2021

\section{Age-Related Changes in Orbits of Ancient Children from Zaghunluq Cemetery in Xinjiang, China}

\author{
Haijun Li \\ Minzu University of China \\ Huimin Chen \\ Minzu University of China \\ Letian $\mathrm{He}$ \\ Lanzhou University \\ Liming Liu \\ Minzu University of China \\ Bo Wang \\ Xinjiang Uygur Autonomous Region Museum
}

See next page for additional authors

Follow this and additional works at: https://digitalcommons.wayne.edu/humbiol_preprints

\section{Recommended Citation}

Li, Haijun; Chen, Huimin; He, Letian; Liu, Liming; Wang, Bo; and Xiao, Xiaoyong, "Age-Related Changes in Orbits of Ancient Children from Zaghunluq Cemetery in Xinjiang, China" (2021). Human Biology Open Access Pre-Prints. 183.

https://digitalcommons.wayne.edu/humbiol_preprints/183

This Article is brought to you for free and open access by the WSU Press at DigitalCommons@WayneState. It has been accepted for inclusion in Human Biology Open Access Pre-Prints by an authorized administrator of DigitalCommons@WayneState. 


\section{Authors}

Haijun Li, Huimin Chen, Letian He, Liming Liu, Bo Wang, and Xiaoyong Xiao

This article is available at DigitalCommons@WayneState: https://digitalcommons.wayne.edu/humbiol_preprints/183 


\section{Age-Related Changes in Orbits of Ancient Children from Zaghunluq Cemetery in}

\section{Xinjiang, China}

Haijun Li, ${ }^{1 *}$ Huimin Chen, ${ }^{1}$ Letian $\mathrm{He},{ }^{2 *}$ Liming Liu,,${ }^{1}$ Bo Wang, ${ }^{3}$ and Xiaoyong Xiao ${ }^{1}$

${ }^{1}$ School of Ethnology and Sociology, Minzu University of China, Beijing, China.

${ }^{2}$ School of History and Culture, Lanzhou University, Lanzhou, Gansu, China.

${ }^{3}$ Xinjiang Uygur Autonomous Region Museum, Urumqi, China.

*Correspondence to:

Haijun Li, Minzu University of China, 27 South Zhongguancun Avenue, Beijing 100081, P.R.

China. E-mail: lindavy@163.com.

Letian He, Lanzhou University, School of History and Culture, Lanzhou, Gansu, 73002,

China. E-mail: helt@1zu.edu.cn.

Short Title: Age-Related Changes in Orbits of Ancient Children from Zaghunluq Cemetery

KEY WORDS: ANCIENT CHILDREN, ZAGHUNLUQ CEMETERY, ORBIT, GROWTH

SPURT PERIODS, ORBITAL GROWTH. 


\begin{abstract}
Thirty-eight skull samples of ancient children were analyzed that were excavated from the Zaghunluq cemetery, which dates between 2600 and 1900 cal. yr BP. The orbit features of children during age changes and growth spurt periods were explored by comparing the orbital height, orbital breadth, orbital area, the values of the orbital index, and other measurements among different age groups. The analysis showed significant differences in orbital breadth between the five age groups (2 years, 3-5 years, 6-8 years, 9-11 years, and 12-15 years), while differences in orbital height, orbital area, and orbital index were not significant. It was also found that the growth spurt period of orbital breadth I was during 3-5 years of age, and the growth spurt period of orbital breadth II occurred during 6-8 years of age. However, there were no significant age-related changes in orbital height and orbital area. Notably, the orbital height of a 2 -year-old child has reached $92.7 \%$ of the adult size. This may elucidate the changes in the orbits of children due to age in ancient Xinjiang, China.
\end{abstract}


The orbit is a bony pyramid with four walls: a roof, lateral wall, floor, and medial wall. Human orbits are located on both sides of the nasal root of the face. Its main role is to protect and accommodate the eyeball and ancillary structures. The current research on orbital morphological variation mainly focuses on gender differences, age changes, and ethnic differences.

\section{Gender Differences in Orbital Morphology}

Scholars have conducted in-depth research on the gender differences of orbital morphological variations. Weaver et al. (2010) studied the orbital computed tomography (CT) images of 39 subjects (17-76 years old) and found that the lateral distance measurement and inferior orbital rim perimeter vary significantly between males and females. Orbital width and height measurements vary significantly between the sexes (male > female). Osaki et al. (2002) analyzed and classified orbital morphology from CT images and examined orbital morphology in the Japanese population, then found that orbital morphology was symmetrical on both sides in both sexes and that men had a larger orbital size than women. In Ji et al.'s study (2010), they noted that in men and women respectively, the mean bony orbital volume was $26.02 \mathrm{~cm}^{3}$ and $23.32 \mathrm{~cm}^{3}$, the mean orbital foramen area $11.80 \mathrm{~cm}^{2}$ and $11.10 \mathrm{~cm}^{2}$, the mean orbital rim perimeter $12.65 \mathrm{~cm}$ and $12.20 \mathrm{~cm}$, the mean orbital height $33.35 \mathrm{~mm}$ and $33.22 \mathrm{~mm}$, and the mean orbital breadth $40.02 \mathrm{~mm}$ and $38.00 \mathrm{~mm}$. It was concluded that there were significant differences between men and women in all anatomical parameters other than orbital height. Orbital size was significantly smaller in women than in men; orbital height, however, was similar. This conclusion is similar to Furuta's study (2001) on Japanese 
subjects, who found that the mean orbital volume of Japanese adults was $23.6 \pm 2.0 \mathrm{~cm}^{3}$ in males and $20.9 \pm 1.3 \mathrm{~cm}^{3}$ in females. This viewpoint was also supported by Chau et al. (2004) who studied Chinese people in Hong Kong $\left(22.20 \pm 1.38 \mathrm{~cm}^{3}\right.$ for males, $19.81 \pm 2.23 \mathrm{~cm}^{3}$ for females).

Many scholars have done research on the gender differences in the orbital growth of children. Bentley et al. (2002) pointed out that the orbital volume between males and females before the age of five tends to have no difference. Chen et al. (2006) reported that there is no significant difference in orbital volume between males and females before the age of 14, and the orbital volume of men after the age of 14 is larger than that of women. Yang et al. (2009) found that the orbital volume of boys is larger than that of girls after the age of nine. Yang et al. (2015) found that there was no significant difference in orbital volume between males and females in all age groups among 0-6-year-olds, and the gender had no effect on orbital development of children before the age of six.

\section{Age-Related Changes in Orbital Morphology}

Many scholars have paid attention to the changes in the orbit that occur during childhood. The orbital region was found to display clear variability in its growth rate. The interorbital region changes relatively little after birth, while the lateral wall of the orbit continues to grow throughout childhood, producing a wider adult orbit (Waitzman et al., 1992; Dixon et al., 1997). Scott (1954) pointed out that the orbital height at birth is $55 \%$ of that of the adult and $79 \%$ of total growth at three years of age; at seven years of age, the orbital height is $94 \%$ of that of the adult while the facial height is only $80 \%$. Carr et al. (1992) believed that the 
growth of the bony orbit reached $85 \%$ to $90 \%$ of the adult size by the age of 5-7 years and then slowed down; after the age of 12 , the growth of the orbits was close to $95 \%$ or more of that of an adult. Barbeito-Andrés et al. (2016) measured the orbital cross-section of humans aged 0-3 years and analyzed the data to find that in the first year after the birth of the child, the orbital size increased rapidly; subsequently, the size of the orbit increased slowly until the age of six. Bentley et al. (2002) found that in infants and young children, the average orbital volume has reached $56 \%$ of the orbital volume at the age of 15 years. When a child reaches five years of age, the average orbital volume has reached $77 \%$ of the orbital volume at the age of 15 . The age of five is a turning point for orbital growth. The volume of the orbit increases linearly before the age of five, and then the growth rate decreases significantly. Furuta (2001) noted that age has a significant impact on orbit volume by a study on 109 subjects (including 74 males and 35 females), orbital volume was shown to grow rapidly until 14.9 years of age in boys and 10.9 years of age in girls, and orbital volume had then reached $95 \%$ of adult growth by these times. In the human, orbital growth is completed much earlier than other facial and general skeletal growth. Yang et al. (2015) analyzed the relationship between orbital volume and age of children (aged 0-6) using a one-way linear correlation and regression and found that the average orbital volume of normal children at birth was $12.57 \pm$ $3.80 \mathrm{~cm}^{3}$; by the age of six, the orbital volume increased to $19.34 \pm 1.86 \mathrm{~cm}^{3}$, with an average annual increase of $1.13 \mathrm{~cm}^{3}$. The orbital volume of children aged $0-6$ has a linear positive correlation with age. Chau et al. (2004) found that the majority of orbital growth occurs in the first years of life, the orbit was about $60 \%$ of the adult size by the age of three years, and the rate of orbit growth was less rapid after three years of age; by the age of 10 years, the orbit 
was $78 \%$ of the mature volume, with an average size of $16 \mathrm{~cm}^{3}$. The above studies show that orbital growth in childhood is significant, and at a specific age, the level of orbital growth is close to that of adults.

Some scholars have also paid attention to the variation of orbital size in adulthood. Kim et al. (2020) studied the facial CT images of 96 subjects (48 males and 48 females) aged between 19 and 60 years and found that the vertical dimension measurements of the orbit did not vary with age in both male and female populations $(p=0.069$ and $p=0.065$, respectively). It is interesting that in the male population, the horizontal and rim dimensions showed a significant decrease with age ( $p=0.025$ and $p=0.040$, respectively). Furuta's study (2001) showed that orbital volume tended to increase in men and women aged 40 years or older. In Mendelson's study (2007), facial CT scans were performed for 62 patients ranging in age from 21 to 70 years who were divided into three age groups (21-30 years, 41-50 years, and 61-70 years), and he found that there was no statistically significant difference between the age groups in either the length of the orbital roof $(p=0.2)$ or the length of the orbital floor $(p=0.3)$. However, results also showed that the lengths of the superior and inferior orbits remained constant with increasing age. Compared to childhood growth, the orbital bones are nearly mature and the growth slowed down.

\section{Ethnic Differences in Orbital Morphology}

Many scholars have explored orbital volume. The average orbital volume of a Chinese adult was $26.02 \mathrm{~cm}^{3}$ in men and $23.32 \mathrm{~cm}^{3}$ in women in Ji's study (2010). This was different from the results of Ye et al. (2006) in Korean subjects $\left(23.94 \pm 3.47 \mathrm{~cm}^{3}\right)$ and the results of 
Regensburg et al. (2008) in Caucasians $\left(25.17 \pm 0.06 \mathrm{~cm}^{3}\right)$, but larger than those reported by Furuta (2001) in Japanese subjects $\left(23.6 \pm 2.0 \mathrm{~cm}^{3}\right.$ for males, $20.9 \pm 1.3 \mathrm{~cm}^{3}$ for females), Chau et al. (2004) in Chinese subjects from Hong Kong $\left(22.20 \pm 1.38 \mathrm{~cm}^{3}\right.$ for males, $19.81 \pm$ $2.23 \mathrm{~cm}^{3}$ for females), and by Acer et al. (2009) in Turkish subjects $\left(17.84 \mathrm{~cm}^{3}\right.$ by the waterfilling method and $17.05 \mathrm{~cm}^{3}$ by the point-counting method). These differences may be due to race, measurement methods, or sample size. Among modern human groups, there is considerable variability in the characteristics of the orbit (Cameron, 1920; Villiers, 1968; Masters, 2008; Lu, 2007). Kim et al. (2020) compared the morphometric parameters of the orbit in the Turkish and Korean population, and they found that there were no significant differences in vertical dimensions; however, horizontal dimensions showed a significant difference between the two populations.

Morphology of the orbits varies among ethnic groups. Lahr (1996) stated that the orbit shape of East Asians was too variable to be generalized. However, a taller, narrower, and more rounded orbit was found to be highly common for East Asian individuals, and this was supported by a series of studies (Pan, 1933; Brown, 1992; Brown and Maeda, 2004; Masters, 2008). Other studies have suggested an elliptical or square orbit aperture for Chinese populations (Lu, 2007). Villiers (1968) proposed a hypsiconch and rectangular orbit to be characteristic of Bantu-speaking South African populations. Masters (2008), however, proposed that Africans were characterized by a much shorter orbit. Xing et al. (2013) suggested that the Asian orbital contour was generally tall and rounded, and its inferior contour was symmetrical. European orbits tended to be square and more inclined, whereas African orbits tended to be shorter. 
Past research has mainly focused on the study of the differences in orbital morphology due to gender, age, and ethnicity, and it has revealed characteristics of orbital variability and growth of modern children. However, due to limited materials, few scholars have studied the age changes of the orbits of ancient children, and further research needs to be performed. Based on the children's skulls unearthed from the Zaghunluq cemetery in Xinjiang, this article intends to explore the changes of the orbital dimensions of ancient children associated with age, which not only provides clues for orbital growth in ancient children, but also for craniofacial morphological research. Additionally, because the composition of the orbit involves multiple facial bones, this research can also provide information for the overall development of the face of ancient children, as well as provide a numerical reference of a normal variation range for use in the diagnosis of orbital diseases.

\section{Materials and Methods}

\section{Research Materials}

The studied samples consisted of 38 well-preserved children's skulls (2-15 years) maintained at the Xinjiang Uygur Autonomous Region Museum and excavated from the Zaghunluq cemetery (located in Zaghunluq Village, Qiemo county), which is one of the largest ancient tomb complexes in the northern slope of the Kunlun Mountains. The Zaghunluq tomb site, dating between 2600 and 1900 cal. yr BP, belonged to the time of the ancient state of Qiemo (Fig. 1). Wang et al. (2016) carried out a detailed study on the Zaghunluq cemetery, and Fu et al. (2018) conducted morphological studies on the adult craniums. These studies might shed light on the physical characteristics of Zaghunluq's ancient humans. 


\section{Research Methods}

Age Identification and Grouping. With reference to the Anthropometric Manual (Shao, 1985) and The Human Bone Manual (White et al., 2018), comprehensive age identification was conducted according to the closure of the anterior fontanelle, the emergence of deciduous and permanent teeth, tooth abrasion, and other conditions. Children's teeth erupt gradually in pairs in a certain time. Most deciduous teeth emerge during the second year of life. The two permanent incisors and the first permanent molar usually emerge between six and eight years. Most permanent canines, premolars, and second molars emerge between 10 and 12 years. The third molar emerges around 18 years. In addition, the bregma usually closes between 1.5-2 years old, and tooth attrition also has certain characteristics in particular age groups. Based on the above methods, the age groups of the ancient children at the site could be inferred.

As seen in Fig. 2, the samples were divided into five age groups according to the age identification results: the 2 years group ( 2 cases), the 3-5 years group ( 7 cases), the 6-8 years group ( 8 cases), the $9-11$ years group ( 8 cases), and the $12-15$ years group (13 cases). The above contains a total of 38 cases.

Photography. Because the outer contour of the human bony orbit is a three-dimensional structure, the entire contour is not in the same plane. In order to standardize this, the cranium was placed with its orbital vent facing upward and adjusted until the superior margin of the orbit was in a horizontal position. Subsequently, while encompassing as much of the orbital contour as possible, a standard plane was established to eliminate the influence of subjective 
errors (Xing et al., 2013). After the specimens were adjusted following the standardization procedure above, they were photographed. All pictures were taken by one author, and for scale, a millimeter ruler was placed parallel to the orbital plane. When the anterior views of the skulls were photographed, they were placed on the Frankfurt horizontal plane.

Orbital Measurement and Related Statistical Methods. The following measurements were taken on the standardized photographs:

1. Orbital height: maximum diameter of orbital entrance perpendicular to orbital breadth.

2. Orbital breadth I: the distance from the dacryon (d) to the ectoconchion (ec).

3. Orbital breadth II: the distance from the maxillofrontale ( $\mathrm{mf})$ to the ectoconchion (ec).

4. Upper facial height: the distance from the nasion (n) to the superior prosthion (pr).

5. Bizygomatic breadth: the distance between each zygomatic arch.

Then, the orbital index was calculated based on the above measurements. The model can be expressed as follows:

Orbital index $=100 \% \times \frac{\text { The orbital height }}{\text { The orbital breadth }}$

According to the graphic scale, the area of the orbit was calculated by using AUTOCAD software (Fig. 3). The determination of the orbital contour was determined according to Xing's methods (Xing et al., 2013). The projected areas of the anterior views of the skulls were calculated by using AUTOCAD software to draw the contours, and then the area was calculated according to the scale. 
SPSS statistical software was used to conduct ANOVA analysis and multiple comparisons of measurement values of different age groups (utilizing the LSD method). We then calculated the rate of change between different age groups. The main formula is as follows:

Rate of change $=100 \% \times \frac{X_{2}-X_{1}}{X_{1}} \quad\left(X_{1}\right.$ and $X_{2}$ represent the average of the same measurement values of the two younger and older age groups.)

\section{Results}

The comparisons of the orbital height, orbital breadth, orbital index, orbital area, upper facial height, and bizygomatic breadth in different age groups are shown in Table 1.

\section{Comparison of the Orbital Breadth in Each Age Group}

ANOVA showed that there were significant differences in the orbital breadth I in the five age groups (2 years, 3-5 years, 6-8 years, 9-11 years, and 12-15 years). Multiple comparisons of the LSD showed a significant difference between the 2 years age group and the 3-5 years age group $(P=0.040)$, no significant difference between the $3-5$ years age group and the 6-8 years age group $(P=0.173)$, no significant difference between the 6-8 years age group and the 9-11 years age group $(P=0.751)$, and a near significant difference between the 9-11 years age group and the $12-15$ years age group $(P=0.067)$. The scatter diagram of the orbital breadth I and the orbital height is shown in Fig. 4.

ANOVA showed that there were significant differences in the orbital breadth II in the five age groups (2 years, 3-5 years, 6-8 years, 9-11 years, and 12-15 years). Multiple 
comparisons of the LSD showed no significant difference between the 2 years age group and the 3-5 years age group $(P=0.224)$, a significant difference between the 3-5 years age group and the 6-8 years age group $(P=0.003)$, no significant difference between the 6-8 years age group and the 9-11 years age group $(P=0.819)$, and no significant difference between the 911 years age group and the $12-15$ years age group $(P=0.183)$. The scatter diagram of the orbital breadth II and the orbital height is shown in Fig. 5.

For orbital breadth I, the average of the 2 years age group, 3-5 years age group, 6-8 years age group, and the $9-11$ years age group accounted for $87.4 \%, 93.6 \%, 96.4 \%$, and $96.9 \%$ of the orbital breadth I of the $12-15$ years age group, respectively. For orbital breadth II, the average of the 2 years age group, 3-5 years age group, 6-8 years age group, and 9-11 years age group accounted for $89.7 \%, 92.8 \%, 98.5 \%$, and $97.9 \%$ of the orbital breadth II of the $12-15$ years age group, respectively.

\section{Comparison of Orbital Height in Each Age Group}

ANOVA showed no significant differences in the orbital height in the five age groups (2 years, 3-5 years, 6-8 years, 9-11 years, and 12-15 years), indicating that there was no significant increase in the orbital height of ancient children aged 2-15 years. The change rate of the orbital height was high between the 2 years age group and the 3-5 years age group $(6.07 \%, P>0.05)$, while the change rate between the 6-8 years age group and the 9-11 years age group was negative $(-4.58 \%, P>0.05)$. 
The average orbital height of the 2 years age group, the 3-5 years age group, the 6-8 years age group, and the 9-11 years age group accounted for $92.7 \%, 98.3 \%, 101.3 \%$, and $96.7 \%$ of the orbital height of the $12-15$ years age group, respectively.

\section{Comparison of the Orbital Index in Each Age Group}

ANOVA showed no significant differences in the orbital index I and orbital index II in the five age groups (2 years, 3-5 years, 6-8 years, 9-11 years, and 12-15 years).

\section{Comparison of the Orbital Area in Each Age Group}

ANOVA showed no significant differences in the orbital area in the five age groups (2 years, 3-5 years, 6-8 years, 9-11 years, and 12-15 years). The average orbital area of the 2 years age group, the 3-5 years age group, the 6-8 years age group, and the 9-11 years age group accounted for $92.7 \%, 97.6 \%, 97.1 \%$, and $97.1 \%$ of the orbital area of the $12-15$ years age group, respectively.

\section{Comparison of the Projected Area of the Anterior View of Skulls in Each Age Group}

The average projected areas of the anterior view of the skulls in the five age groups (2 years, 3-5 years, 6-8 years, 9-11 years, and 12-15 years) were $72.63 \mathrm{~cm}^{2}, 82.81 \mathrm{~cm}^{2}, 88.18 \mathrm{~cm}^{2}$, $88.02 \mathrm{~cm}^{2}$, and $98.44 \mathrm{~cm}^{2}$, respectively. According to the analysis of variance, there was a significant difference in the anterior area of the skulls between children of different age groups $(P=0.000)$, reflecting that the anterior area of the skulls of children increased with age. 


\section{Comparison of the Upper Facial Height in Each Age Group}

ANOVA showed that there were significant differences in the upper facial height in the five age groups (2 years, 3-5 years, 6-8 years, 9-11 years, and 12-15 years). Multiple comparisons of the LSD showed a significant difference between the 2 years age group and the 3-5 years age group $(P=0.040)$, a significant difference between the 3-5 years age group and the 6-8 years age group $(P=0.044)$, no significant difference between the 6-8 years age group and the 9-11 years age group $(P=0.810)$, and a significant difference between the 9-11 years age group and the $12-15$ years age group $(P=0.001)$.

\section{Comparison of the Bizygomatic Breadth in Each Age Group}

ANOVA showed that there were significant differences in the bizygomatic breadth in the five age groups (2 years, 3-5 years, 6-8 years, 9-11 years, and 12-15 years). Multiple comparisons of the LSD showed a significant difference between the 2 years age group and the 3-5 years age group $(P=0.041)$, no significant difference between the 3-5 years age group and the 6-8 years age group $(P=0.084)$, no significant difference between the 6-8 years age group and the 9-11 years age group $(P=0.656)$, and a significant difference between the 9-11 years age group and the $12-15$ years age group $(P=0.000)$.

\section{Discussion}

\section{Age-Related Changes in Orbital Breadth}

There were significant differences in the orbital breadth $\mathrm{I}$ in the five age groups (2 years, 3-5 
years, 6-8 years, 9-11 years, and 12-15 years). According to multiple comparisons of the LSD, there was a significant difference between the 2 years age group and the 3-5 years age group $(P=0.040)$, which suggested that the growth spurt period of the orbital breadth I occurred at 3-5 years in ancient children.

There was a significant difference in the orbital breadth II in the five age groups (2 years, 3-5 years, 6-8 years, 9-11 years, and 12-15 years). According to multiple comparisons of the LSD, there was a significant difference between the 3-5 years age group and the 6-8 years age group $(P=0.003)$. This indicates that orbital breadth II increased greatly at the age of 6-8 years in ancient children.

\section{Age-Related Changes in Orbital Height}

There were no significant differences in the orbital height in the five age groups ( 2 years, 3-5 years, 6-8 years, 9-11 years, and 12-15 years). This suggested that there was almost no remarkable increase in orbital height between the ages of 2 and 15 , and that there was no growth spurt period. The orbital height of a 2 -year-old child has reached $92.7 \%$ of the adult size. Significant differences in orbital width (vertical axis direction) were found between these age groups, while there was no significant difference in the horizontal axis direction (orbital height; Fig. 4, Fig. 5).

\section{Age-Related Changes in Orbital Index}

There were no significant differences in the orbital index I and orbital index II in the five age groups (2 years, 3-5 years, 6-8 years, 9-11 years, and 12-15 years), which suggested that at 
two years of age, the orbital index value reached the 12-15 years level, and there was no significant change. This showed that although the growth rate of the orbital breadth is greater than the growth rate of the orbital height during the ages of 2-15 years, the orbital index has relatively little change.

\section{Age-Related Changes in Orbital Area}

There were no significant differences in the orbital area in the five age groups (2 years, 3-5 years, 6-8 years, 9-11 years, and 12-15 years). According to comparisons, the average orbital area of the 2 years age group, 3-5 years age group, 6-8 years age group, and the 9-11 years age group accounted for $92.7 \%, 97.6 \%, 97.1 \%$, and $97.1 \%$ of the orbital area of the $12-15$ years age group, respectively. It was shown that the orbital area of the two years age group almost reaches the growth level of the 12-15 years age group (Fig. 6, Fig. 7).

\section{Age-Related Changes in Upper Facial Height and the Ratio of Orbital Height to Upper}

\section{Facial Height}

Significant differences were found in the upper facial height in the five age groups ( 2 years, 3-5 years, 6-8 years, 9-11 years, and 12-15 years). According to multiple comparisons of the LSD, there were significant differences between the 2 years age group and 3-5 years age group $(P=0.040)$, the 3-5 years age group and the 6-8 years age group $(P=0.044)$, and the 9-11 years age group and the $12-15$ years age group $(P=0.001)$. This suggested that the growth spurt period of upper facial height mainly occurred at 3-5 years old, 6-8 years old, and 12-15 years old. 
By analysis, the proportions of the orbital height to the upper facial height in the five age groups were $63.2 \%, 59.5 \%, 57.2 \%, 54.2 \%$, and $51.1 \%$, respectively. This suggested that the ratio of the orbital height to the upper facial height gradually decreases with age. With the increase of age, the growth rate of the orbital height is slower than the growth rate of the upper facial height.

\section{Age-Related Changes in Bizygomatic Breadth and the Ratio of Orbital Breadth to}

\section{Bizygomatic Breadth}

Significant differences were found in the bizygomatic breadth in the five age groups (2 years, 3-5 years, 6-8 years, 9-11 years, and 12-15 years). According to multiple comparisons of the LSD, there was a significant difference between the 2 years age group and 3-5 years age group $(P=0.041)$, and the $9-11$ years age group and the $12-15$ years age group $(P=0.001)$. This suggested that the growth spurt period of bizygomatic breadth mainly occurred at 3-5 years old and 12-15 years old.

By analysis, the proportions of the orbital breadth I to the bizygomatic breadth in the five age groups were $33.84 \%, 32.97 \%, 32.36 \%, 32.16 \%$, and $30.39 \%$, respectively. This suggested that the ratio of the orbital breadth I to the bizygomatic breadth gradually decreases with age. With the increase of age, the growth rate of the orbital breadth I is slower than the growth rate of the bizygomatic breadth.

The proportions of the orbital breadth II to the bizygomatic breadth in the five age groups were $37.62 \%, 35.43 \%, 35.83 \%, 35.22 \%$, and $32.94 \%$, respectively. This suggested that the ratio of the orbital breadth II to the bizygomatic breadth gradually decreases with age. 
With the increase of age, the growth rate of the orbital breadth II is slower than the growth rate of the bizygomatic breadth.

\section{Age-Related Changes in the Ratio of Orbital Area to the Projected Area of Anterior Skulls}

By analysis, the proportion of the orbital area to the anterior area of the skulls in the five age groups (2 years, 3-5 years, 6-8 years, 9-11 years, and 12-15 years) were 21.4\%, 19.8\%, $18.5 \%, 18.5 \%$, and $17.0 \%$, respectively. This suggested that the ratio of the orbital area to the anterior area gradually decreases with age. With the increase of age, the growth rate of the anterior area of the child's skull is faster than the growth rate of the orbit (Fig. 6, Fig. 7).

\section{Orbital Growth in Ancient Children}

According to the age-related differences of orbital size and orbital index, it is suggested that the orbital breadth I increased significantly at the age of 3-5 years and orbital breadth II increased significantly at 6-8 years of age. However, orbital height of ancient children in this site had not increased significantly since the age of two, and it basically reached adult size at the age of two. In addition, the ratios of children's orbital height to upper surface height, orbital breadth to bizygomatic breadth, and orbital area to projected area of anterior skulls gradually decreased with age, which means that the orbital growth rate of children was significantly slower than the facial growth rate. The proportion of the orbits in the face decreases with age, and the relative proportion of the orbit size of children is larger than that of adults. This may explain why the eyes of modern children are relatively larger than that of adults. 


\section{Conclusion}

The orbital breadth differences among the five age groups of the ancient children of the Zaghunluq site were significant, and the orbital breadth increased with age. The average orbital breadth I of the two years age group accounted for $87.4 \%$ of the adult group (12-15 years age group). The average orbital breadth II in the two years age group accounted for $89.7 \%$ of the adult group (12-15 years age group). This supports the idea put forward by Waitzman et al. (Waitzman et al., 1992; Dixon et al., 1997), who believed that the interorbital region changes relatively little after birth, while the lateral wall of the orbit continues to grow throughout childhood, producing a wider adult orbit.

The growth spurt period of the orbital breadth I occurred at the age of 3-5 years, and that of the orbital breadth II occurred at the age of 6-8 years. This conclusion is different from Carr et al.'s (1992) view that the growth of the orbital bone after 5-7 years is slow. In addition, the orbital height of children has almost no significant growth changes from 2 to 15 years old, and there is no growth spurt period. At two years of age, the child's orbital height has reached $92.7 \%$ of the adult size. This is different from that of scholar Scott's (1954) view, who believes that the orbital height of children is $94 \%$ of the size of adults at the age of seven. The reason for these differences may be related to the grouping method, sample size, population differences, etc., or it may be related to the nutritional status, physical fitness, and dietary structure of the children in Zaghunluq.

The craniofacial bones of children grow rapidly, and the size of the craniofacial bones from birth to five years old is close to $85 \%$ of that of adults (Waitzman et al., 1992). In this 
study, the ratios of children's orbital height to upper facial height, orbital breadth to bizygomatic breadth, and orbital area to projected area of anterior skulls gradually decreased with age. The face grows rapidly, and its growth rate was greater than that of the orbital region.

No significant change occurred in the orbital area after two years old; that is, the orbital area had no growth spurt period after about two years old. This means that the growth spurt period of the orbit is before two years old. This supports the views of Barbeito-Andrés et al. Similarly, Bentley et al. (2002) also believed that the orbit grows fast before one year of age, and this time is the most critical period. Chau et al. (2004) also believed that the orbital growth was rapid before three years old.

This article briefly explores the features of orbital changes with age by analyzing orbital characteristics and related proportions of ancient children. However, due to the small number of skulls of the children and a relatively small amount of literature, the question of whether these conclusions are universal or not remains to be verified. In order to investigate the orbital growth of ancient children from birth, more samples of children are needed, especially 0-2-year-old orbital samples. We hope that in the future there will be more complete skulls of ancient children available as well as more diversified methods for further exploration of orbital growth and age-related changes in ancient children.

\section{Acknowledgments}

This work has been supported by the grants from the National Social Science Fund of China (Grant No. 19BKG039, 19VJX066). 
Received 22 August 2020; accepted for publication 15 January 2021.

Preprint version. Visit http://digitalcommons.wayne.edu/humbiol/ after publication to acquire the final version. 


\section{Literature Cited}

Acer, N., B. Sahin, H. Ergür et al. 2009. Stereological estimation of the orbital volume: A criterion standard study. J. Craniofac. Surg. 20:921-925.

Barbeito-Andrés, J., M. Anzelmo, F. Ventrice et al. 2016. Morphological integration of the orbital region in a human ontogenetic sample. Anat. Rec. (Hoboken) 299:70-80.

Bentley, R. P., S. Sgouros, K. Natarajan et al. 2002. Normal changes in orbital volume during childhood. J. Neurosurg. 96:742-746.

Brown, P. 1992. Recent human evolution in East Asia and Australasia. Philos. Trans. R. Soc. Lond. B Biol. Sci. 337:235-242.

Brown, P., and T. Maeda. 2004. Post-Pleistocene diachronic change in East Asian facial skeletons: The size, shape and volume of the orbits. Anthropol. Sci. 112:29-40.

Cameron, J. 1920. Contour of orbital aperture in representatives of modern and fossil hominids. Am. J. Phys. Anthropol. 3:476-488.

Carr, M., J. C. Posnick, G. Pron et al. 1992. Cranio-orbito-zygomatic measurements from standard CT scans in unoperated Crouzon and Apert infants: Comparison with normal controls. Cleft Palate Craniofac. J. 29:129-136.

Chau, A., K. Fung, L. Yip et al. 2004. Orbital development in Hong Kong Chinese subjects. Ophthalmic Physiol. Opt. 24:436-439.

Chen, Z., X. H. Zheng, J. B. Xie et al. 2006. Study on the growth of orbital volume in individuals at different ages by computed tomography [in Chinese]. Chin. J. Ophthalmol. 42:222-225.

Dixon, A. D., D. A. N. Hoyte, and O. Ronning. 1997. Fundamentals of craniofacial growth. 
Cleft Palate Craniofac. J. 35:272-275.

Fu, C., and B. Wang. 2018. The study of skulls excavated from tomb No. 64 in the section one of Zhagunluke cemetery, Qiemo county [in Chinese]. Turfanological Res. 2:77102.

Furuta, M. 2001. Measurement of orbital volume by computed tomography: Especially on the growth of the orbit. Jpn. J. Ophthalmol. 45:600-606.

Ji, Y. R., Z. Qian, Y. Dong et al. 2010. Quantitative morphometry of the orbit in Chinese adults based on a three-dimensional reconstruction method. J. Anat. 217:501-506.

Kim, M. J., M. J. Lee, W. S. Jeong et al. 2020. Three-dimensional computer modeling of standard orbital mean shape in Asians. J. Plast. Reconstr. Aesthet. Surg. 73:548-555.

Lu, J. Y. 2007. Variation of orbital shape in modern Chinese [in Chinese]. Acta Anthropol. Sinica 2:128-137.

Masters, M. P. 2008. Modern variation and evolutionary change in the hominin eye orbit. PhD diss., The Ohio State University.

Mendelson, B. C., W. Hartley, M. Scott et al. 2007. Age-related changes of the orbit and midcheek and the implications for facial rejuvenation. Aesthetic Plast. Surg. 31:419423.

Osaki, T., H. Murakami, R. Tamura et al. 2002. Analysis of orbital morphology and its relationship with eyelid morphology. J. Craniofac. Surg. 31:1,875-1,878.

Pan, T. H. 1933. Measurement of the Chinese orbit. J. Anat. 67:596-598. 
Regensburg, N. I., P. H. B. Kok, F. W. Zonneveld et al. 2008. A new and validated CT-based method for the calculation of orbital soft tissue volumes. Invest. Ophthalmol. Vis. Sci. $49: 1,758-1,762$.

Scott, J. H. 1954. The growth of the human face. Proc. R. Soc. Med. 47:91-100.

Shao, X. Q. 1985. The Anthropometric Manual [in Chinese]. Shanghai, CN: Shanghai Lexicographical Publishing House.

Smerdon, D. 2000. Anatomy of the eye and orbit. Curr. Anaesth. Crit. Care 11:286-292.

The Museum of Xijiang Uygur Autonomous Region, CPAM of Bayingolin Mongolian Autonomous Prefecture, CPAM of Charchan County. 2003. Excavation of graveyard No.1 at Zagunluk in Charchan, Xinjiang [in Chinese]. Acta Archaeol. Sinica. 1:91$138,163-178$.

Villiers, H. D. 1968. Non-metric features of the face and palate. In The Skull of the South African Negro, H. D. Villiers, ed. Johannesburg, ZA: Witwatersrand University Press, $120-121$.

Waitzman, A. A., J. C. Posnick, D. C. Armstrong et al. 1992. Craniofacial skeletal measurements based on computed tomography: Part II. Normal values and growth trends. Cleft Palate Craniofac. J. 29:118-128.

Wang, B., M. F. Wang, H. Munawal et al. 2016. Textiles and Treasures of Zaghunluq [in Chinese]. Beijing, CN: Cultural Relics Press.

Weaver, A. A., K. L. Loftis, J. C. Tan et al. 2010. CT based three-dimensional measurement of orbit and eye anthropometry. Invest. Ophthalmol. Vis. Sci. 51:4,892-4,897.

White, T. D., and P. A. Folkens. 2005. The Human Bones Manual. London: Academic Press. 
Whitnal, S. E. 1922. Anatomy of the human orbit and accessory organs of vision. Am. J. Ophthalmol. 5:325-326.

Xing, S., V. Gibbon, R. Clarke et al. 2013. Geometric morphometric analyses of orbit shape in Asian, African, and European human populations. Anthropol. Sci. 121:1-11.

Xinjiang Museum Cultural Relics team. 1998. A brief report on the excavation of No. 5 tombs in Zaghunluq, Qiemo [in Chinese]. J. Xinjiang Cult. Relics. 3:2-18.

Yang, G., Y. Zhang, Q. L. Chang et al. 2015. Measurement of orbital development in children from birth to 6 years of age [in Chinese]. Chin. J. Ophthalmol. 51:576-580.

Yang, H., D. M. Li, Z. C.Wang et al. 2009. Multi-slice spiral CT evaluation of the orbital development in children [in Chinese]. Chin. J. Ophthalmol. 18:321-323.

Ye, J., K. H. Kook, and S. Y. Lee. 2006. Evaluation of computer-based volume measurement and porous polyethylene channel implants in reconstruction of large orbital wall fractures. Invest. Ophthalmol. Vis. Sci. 47:509-513. 
Table 1. Comparison of the Measurement of the Face and Orbits in Different Age Groups

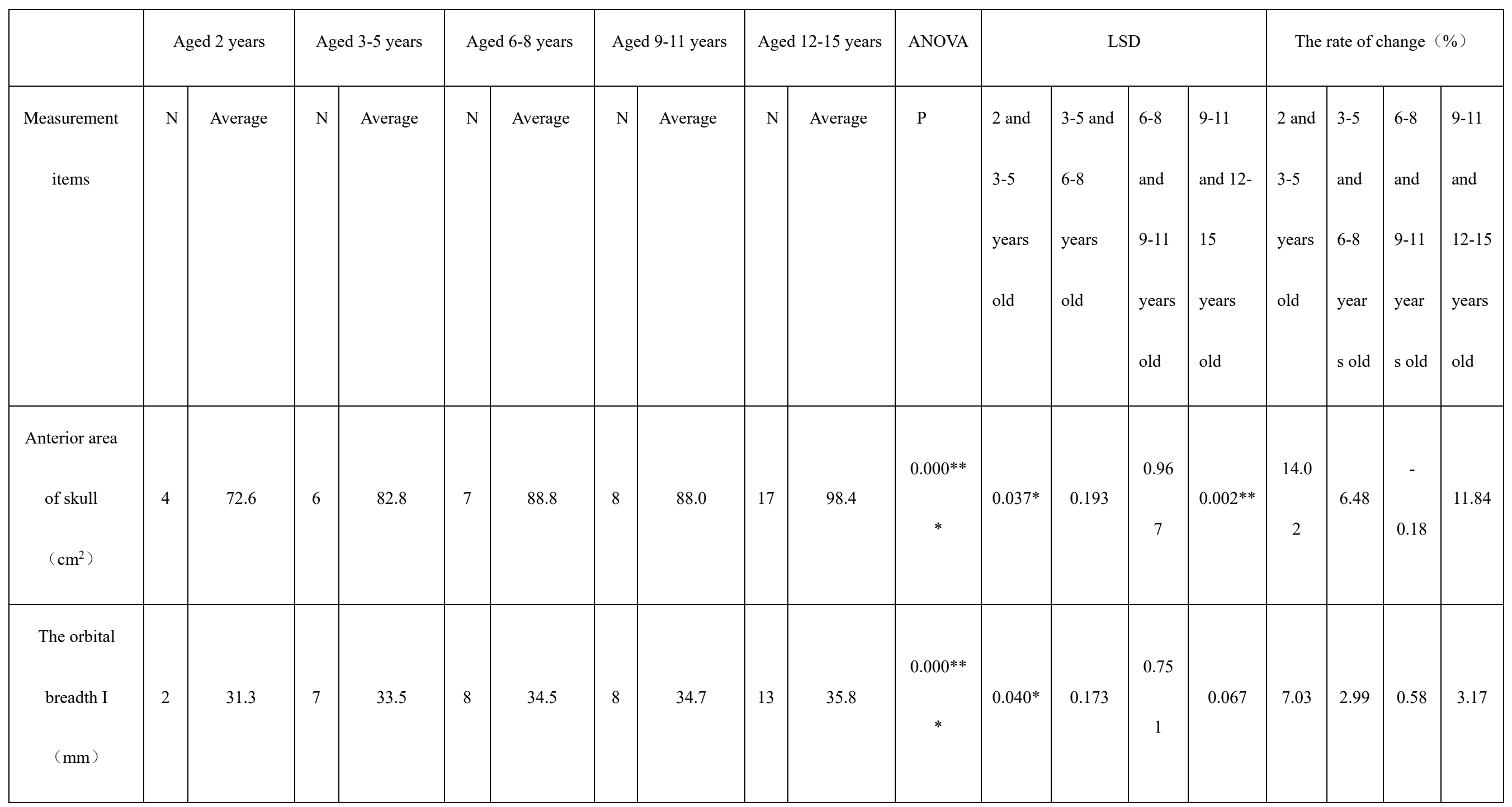

Preprint version. Visit http://digitalcommons.wayne.edu/humbiol/ after publication to acquire the final version. 


\begin{tabular}{|c|c|c|c|c|c|c|c|c|c|c|c|c|c|c|c|c|c|c|c|}
\hline $\begin{array}{l}\text { The orbital } \\
\text { breadth II }\end{array}$ & 2 & 34.8 & 7 & 36.0 & 8 & 38.2 & 8 & 38.0 & 13 & 38.8 & $\begin{array}{c}0.000 * * \\
*\end{array}$ & 0.224 & $\begin{array}{c}0.003 * \\
*\end{array}$ & $\begin{array}{c}0.81 \\
9\end{array}$ & 0.183 & 3.45 & 6.11 & $\begin{array}{c}- \\
0.52\end{array}$ & 2.11 \\
\hline $\begin{array}{l}\text { The orbital } \\
\text { height }(\mathrm{mm})\end{array}$ & 2 & 28.0 & 7 & 29.7 & 8 & 30.6 & 8 & 29.2 & 13 & 30.2 & 0.276 & 0.208 & 0.364 & $\begin{array}{c}0.13 \\
8\end{array}$ & 0.216 & 6.07 & 3.03 & $\begin{array}{c}- \\
4.58\end{array}$ & 3.42 \\
\hline $\begin{array}{c}\text { The orbital } \\
\text { index I }\end{array}$ & 2 & 89.5 & 7 & 88.8 & 8 & 88.8 & 8 & 84.3 & 13 & 84.3 & 0.142 & 0.856 & 0.991 & $\begin{array}{c}0.09 \\
0\end{array}$ & 0.999 & -0.78 & 0 & $\begin{array}{c}- \\
5.07\end{array}$ & 0 \\
\hline $\begin{array}{c}\text { The orbital } \\
\text { index II }\end{array}$ & 2 & 80.4 & 7 & 82.5 & 8 & 80.1 & 8 & 77.0 & 13 & 77.9 & 0.124 & 0.559 & 0.302 & $\begin{array}{c}0.15 \\
6\end{array}$ & 0.646 & 2.61 & $\begin{array}{c}- \\
2.91\end{array}$ & $\begin{array}{c}- \\
3.87\end{array}$ & 1.17 \\
\hline $\begin{array}{c}\text { The orbital area } \\
\left(\mathrm{cm}^{2}\right)\end{array}$ & 3 & 7.8 & 7 & 8.2 & 9 & 8.1 & 9 & 8.1 & 17 & 8.4 & 0.822 & 0.533 & 0.630 & $\begin{array}{c}0.54 \\
4\end{array}$ & 0.532 & 5.28 & $\begin{array}{c}- \\
0.49\end{array}$ & 0 & 2.95 \\
\hline $\begin{array}{l}\text { Upper facial } \\
\text { height }(\mathrm{mm})\end{array}$ & 2 & 44.3 & 7 & 49.9 & 8 & 53.5 & 8 & 53.9 & 13 & 59.1 & $\begin{array}{c}0.000 * * \\
*\end{array}$ & $0.040 *$ & $0.044 *$ & $\begin{array}{r}0.81 \\
0\end{array}$ & 0.001 ** & 12.6 & 7.2 & 0.8 & 9.7 \\
\hline
\end{tabular}

Preprint version. Visit http://digitalcommons.wayne.edu/humbiol/ after publication to acquire the final version. 


\begin{tabular}{|c|c|c|c|c|c|c|c|c|c|c|c|c|c|c|c|c|c|c|c|}
\hline $\begin{array}{l}\text { Bizygomatic } \\
\text { breadth }\end{array}$ & 2 & 92.5 & 7 & 101.6 & 7 & 106.6 & 8 & 107.9 & 13 & 117.8 & $\begin{array}{c}0.000 * * \\
*\end{array}$ & $0.041^{*}$ & 0.084 & $\begin{array}{c}0.65 \\
6\end{array}$ & $0.000^{*}$ & 9.8 & 4.9 & 1.2 & 9.2 \\
\hline$(\mathbf{m m})$ & & & & & & & & & & & & & & & & & & & \\
\hline
\end{tabular}

${ }^{*} \mathrm{p}<0.05, * * \mathrm{p}<0.01, * * * \mathrm{p}<0.000$ 


\section{Figure Captions}

Figure 1. The site of Zaghunluq cemetery.

Figure 2. Comparison of children's skulls in five age groups.

Figure 3. The area of orbit and the anterior view of skulls.

Figure 4. The scatter diagram of the orbital breadth I and the orbital height.

Figure 5. The scatter diagram of the orbital breadth II and the orbital height.

Figure 6. Comparison of different age groups of ancient children (A, B, and $\mathrm{C}$ represent three age groups from child to adult).

Figure 7. The sketch showing the growth trends of orbital morphology in Zaghunluq ancient children. 
Figure 1.

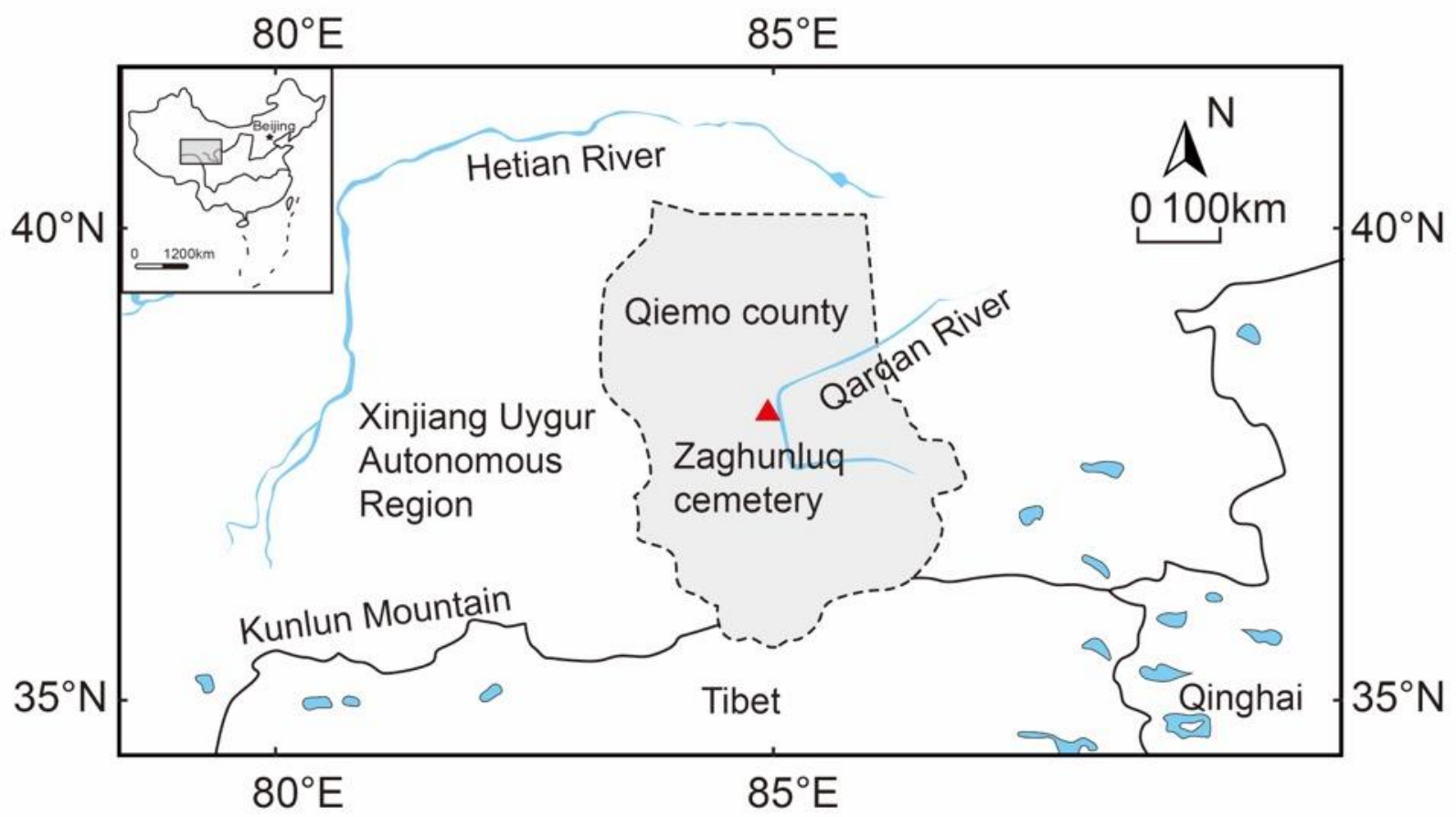

Preprint version. Visit http://digitalcommons.wayne.edu/humbiol/ after publication to acquire the final version. 
Figure 2.

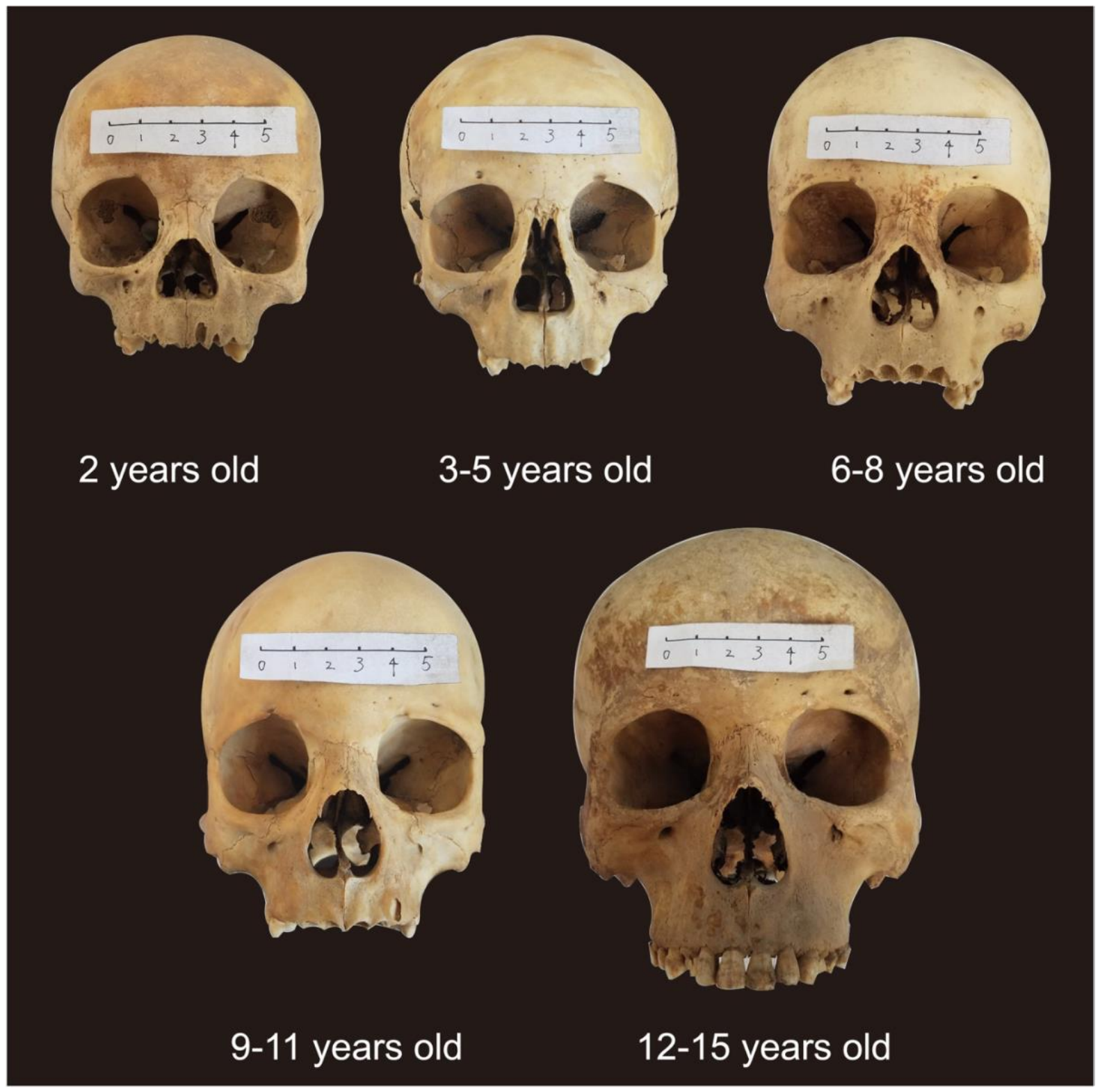


Figure 3.

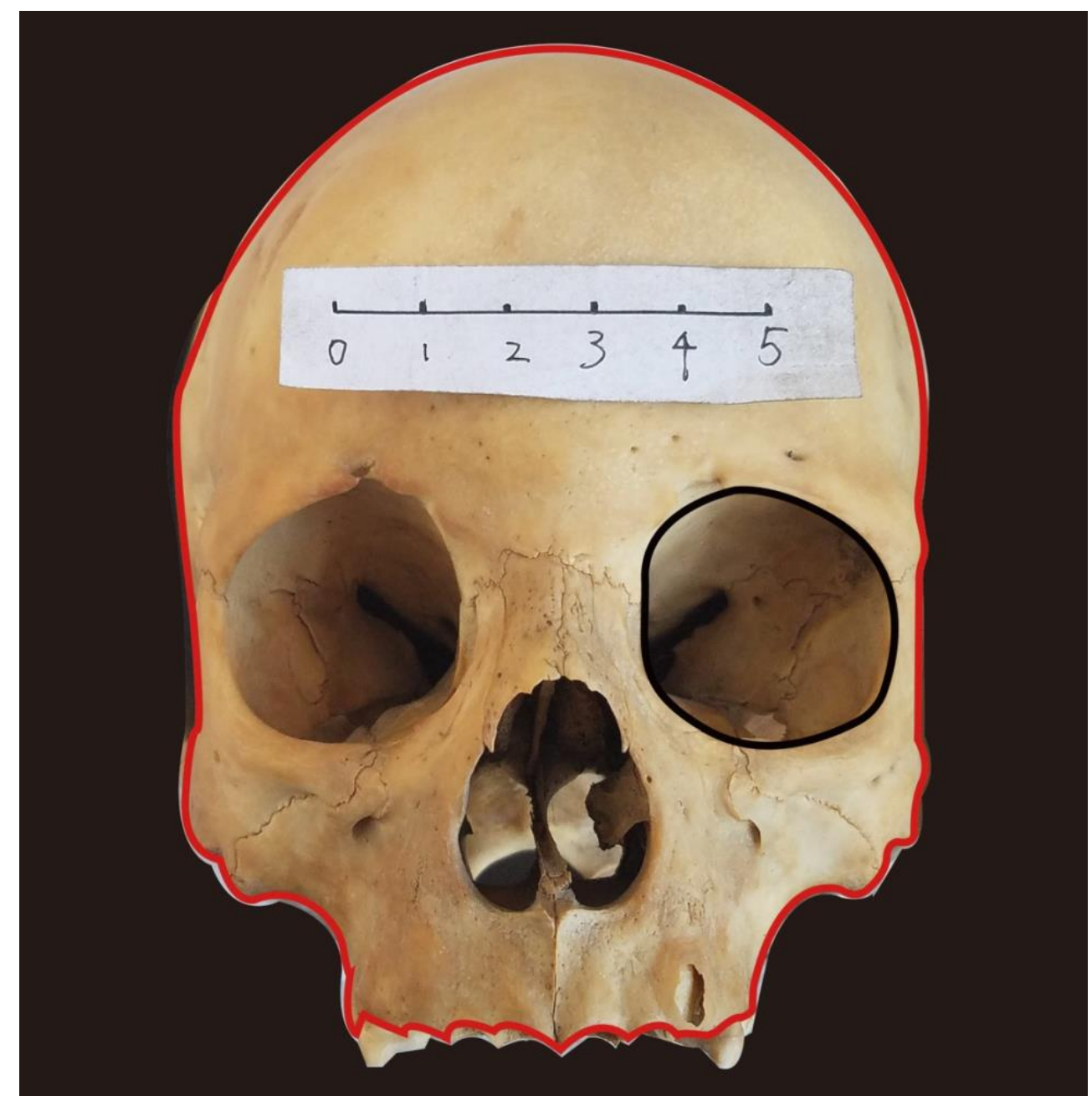

Preprint version. Visit http://digitalcommons.wayne.edu/humbiol/ after publication to acquire the final version. 
Figure 4.

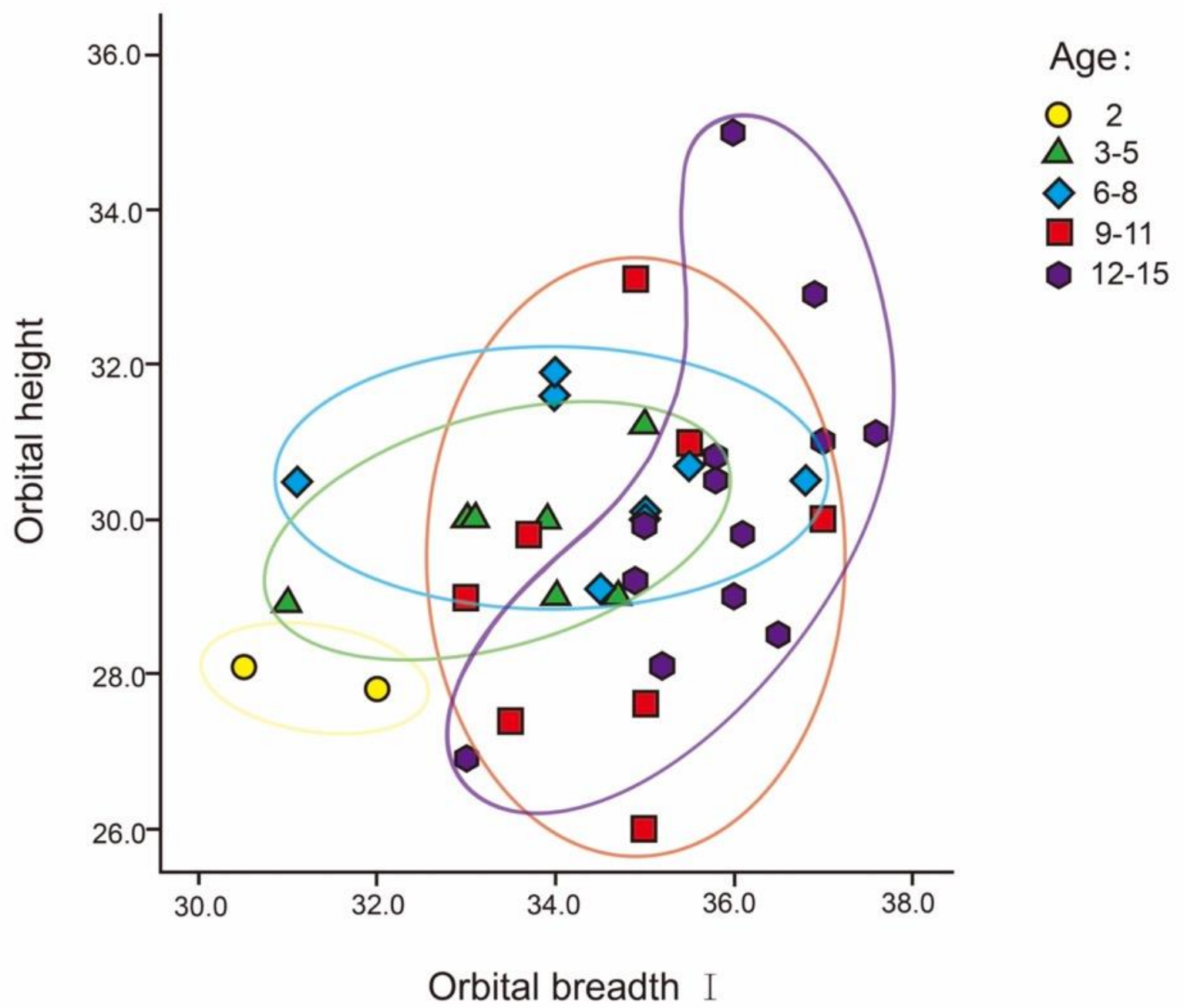

Preprint version. Visit http://digitalcommons.wayne.edu/humbiol/ after publication to acquire the final version. 
Figure 5.

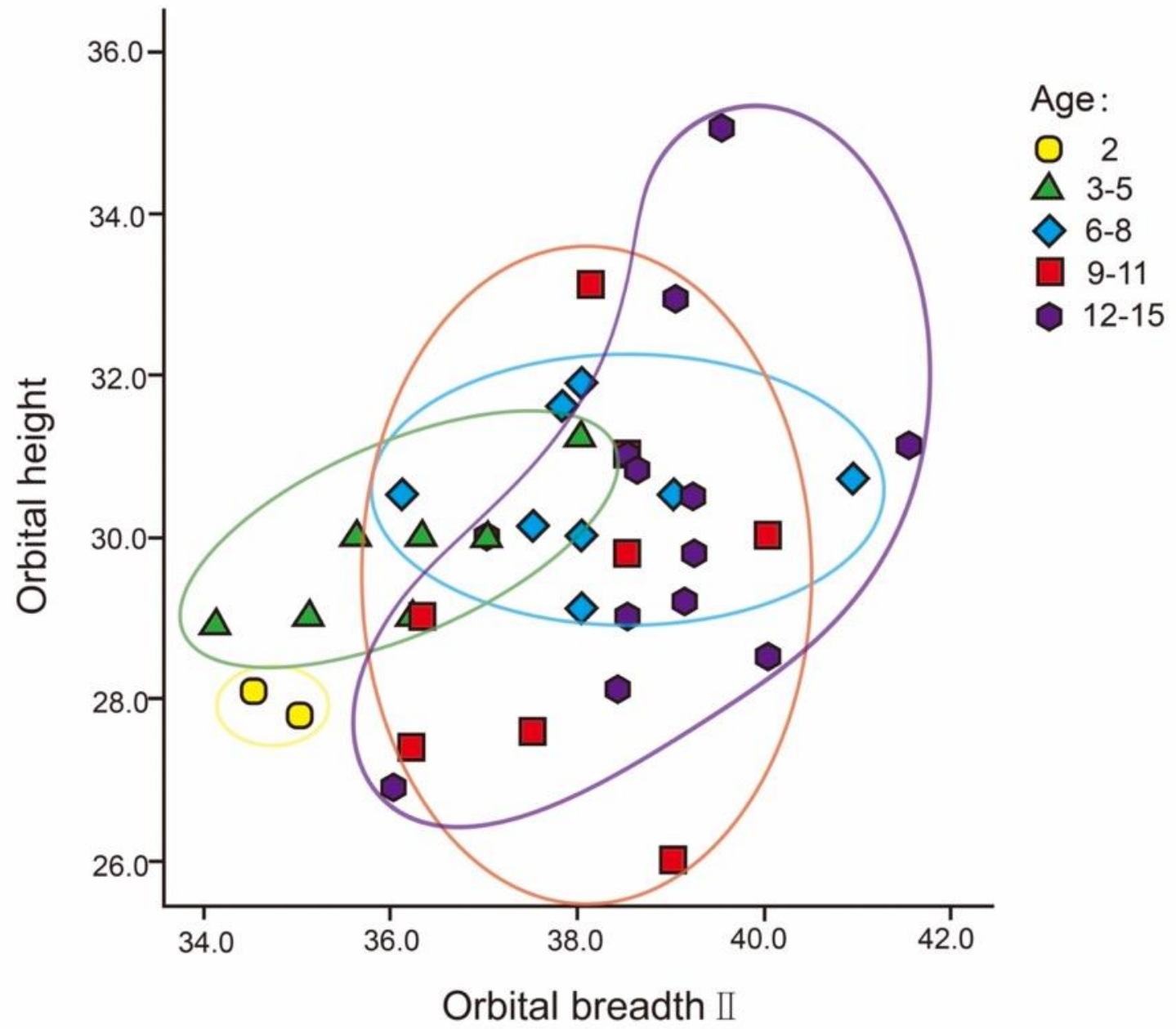


Figure 6.

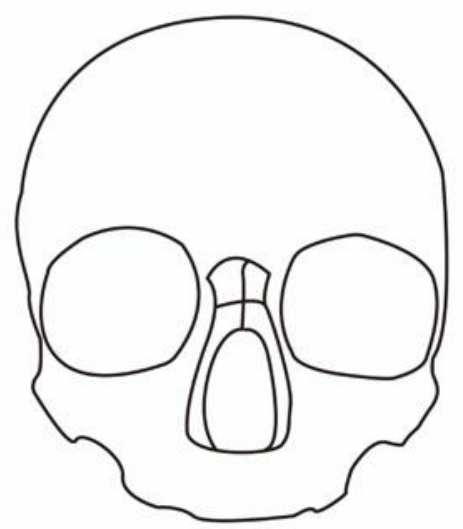

A

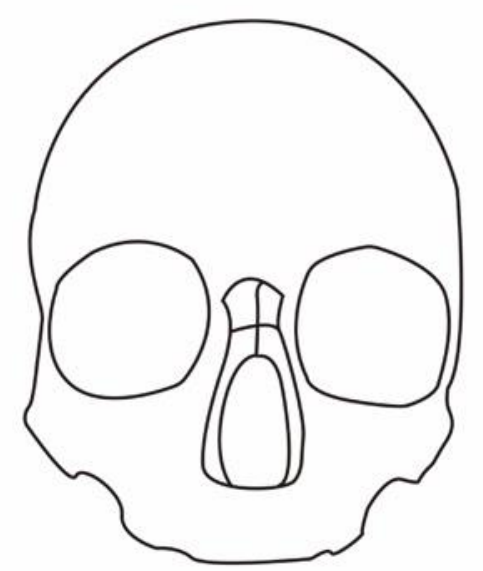

B

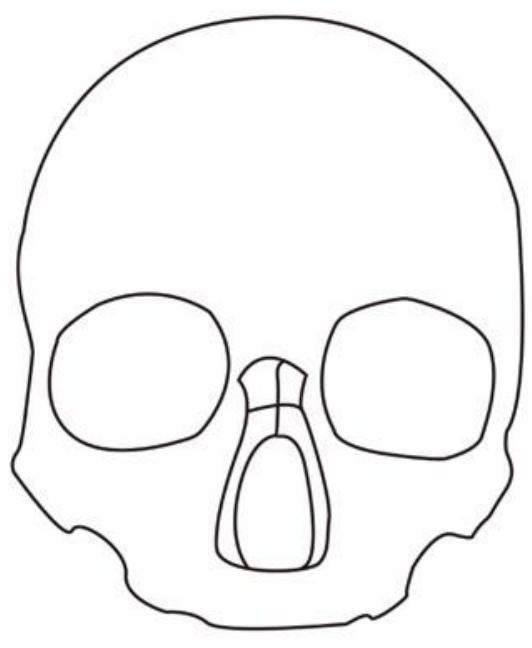

C

Figure 7.

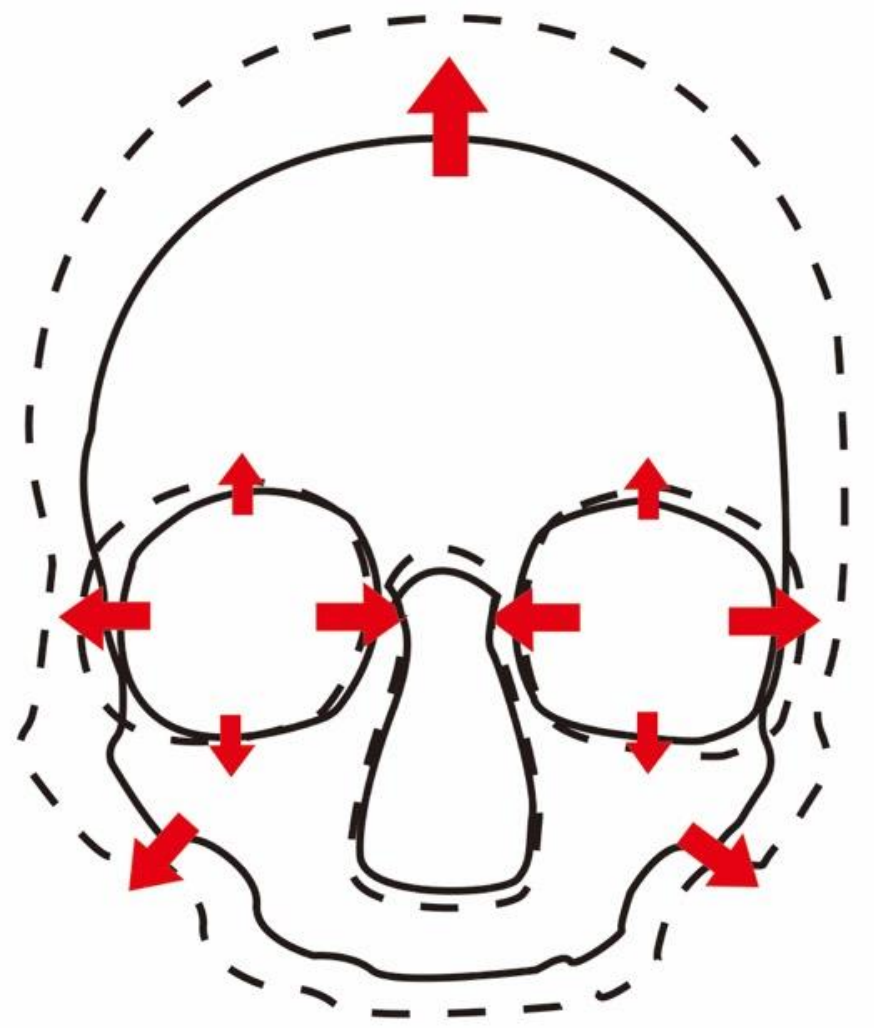

Preprint version. Visit http://digitalcommons.wayne.edu/humbiol/ after publication to acquire the final version. 